\title{
Record of the Japanese eel from the Philippines*1
}

\author{
Osame TABETA, ${ }^{* 2}$ Toru TAKaI, ${ }^{* 2}$ and Isao Matsui*2 \\ (Received March 22, 1975)
}

\begin{abstract}
The authors obtained six specimens of the Japanese eel, Anguilla japonica T. et $\mathrm{S}$. from Cagayan River, near Aparri City, Luzon Island, the Philippines. These specinens were taken as elvers from the river in January and February, 1974, and reared for a period in the Philippines. This is the first record of the Japanese eel from the Philippines and the southernmost locality for the eel. It is likely that the Japanese eel constituted $1-2 \%$ of elvers collected in Cagayan Estuary in January and February, 1974. The authors could not find this eel in the samples taken in the other months. A key to the species was given for the Philippine eels.
\end{abstract}

The Japanese eel has been known as a temperate eel distributed in Eastern Asia from North China throughout Mainland China, Japan, Korea and Taiwan to Tongking Province, North Vietnam. ${ }^{1)}$ Six specimens of eel recently were sent to the authors from the Philippines. Close examination of the specimens revealed that they were all the Japanese eel, Anguilla japonica Temminck and SCHLFGL. This is the first record of the eel from the Philippines and the southernmost locality for the Japanese eel. A description of the present specimens and a key to the species of the genus Anguilla in the Philippines are given in this paper.

\section{Materials and methods}

The specimens were selected from the eels which were collected as elvers in Cagayan Estuary of Luzon Island and reared in eel ponds. Three smaller specimens, 99.0-134.5 $\mathrm{mm}$ in total length, are derived from elvers collected in January, 1974 and reared in a pond at Aparri for two months, while three larger specimens, $233.0-281.0 \mathrm{~mm}$ in total length, were collected as elvers in February, 1974 and reared in a pond at Quezon for eight months. All the specimens were sent to the authors from Mr. Tomohiro IMAMURA, an expert on eel culture, of Quezon, the Philippines, and preserved in $10 \%$ neutral formalin. Examination of the specimens was made under a binocular microscope following the methods adopted by EGE $^{1)}$ and TABETA et al. ${ }^{2}$ Vertebral counts were determined by means of $\mathrm{X}$-ray photographs and fin rays were counted after alizarine treatment.

\section{Description}

Six specimens, 99.0-281.0 mm in total length (Cat. SUF PH-74-1001 6).

*1 Contribution from the Shimonoseki University of Fisheries, No. 739.

*2 Department of Aquiculture \& Biology, Shimonoseki University of Fisheries, Yoshimi, Shimonoseki, Japan (多部田修・高井 徹・松井 魁: 水産大学校增殖学科) 
The description given below is based mainly on a specimen of $281.0 \mathrm{~mm}$ in total length (SUF PH-74-1005, Fig. 1). The fin rays and branchiostegals were counted in a specimen of $233.0 \mathrm{~mm}$ in total length (SUF PH-74-1004). The other specimens were utilized to show the range of characters as shown in parentheses.

Of total length, head $10.7 \%(10.5-12.0 \%)$, predorsal $26.6(26.6-29.9)$, preanal 36.5 (36.5-38.2), ano-dorsal 9.1 (8.0-9.1), depth just behind eye $2.6(2.3-2.9)$, at pectoral base $3.7(3.7-5.0)$, at vent $4.5(4.3-5.2)$, maximum width 3.7 (3.3-3.7). Of head length, snout $17.3 \%(15.7-19.7 \%)$, eye $8.4(8.1-8.8)$, upper jaw $22.7(22.7-26.2)$, lower jaw 24.0 (24.0 27.4), pectoral fin length $37.4(29.0-37.4)$, branchial aperture $8.4(-)$. Total vertebrae $116(115,116)$, predorsal $26(26-30)$, preanal $36(36-39)$, ano-dorsal $9(8-10)$, abdominal $43(43-45)$, caudal $73(71-73)$. Branchiostegals 12 . Dorsal rays 251 , anal 230 , pectoral 18 , caudal 10 .

Body elongate, slender, subcylindrical in front, compressed backward with the greatest depth and width at the midpoint between vent and dorsal origin. Head short, a little less than one-ninth of total length, depressed anteriorly, subcylindrical at nape, its depth at gill-opening subequal to its width at the same region. Snout rather short, its tip broadly rounded in dorsal view. Eye very small, subequal to half of snout length, subcutaneous, suprolateral. Interorbital space moderate, flat. Nostrils two: anterior nostril in a short tube near tip of snout, protruding over upper jaw; posterior nostril slit-like in front of eye. Upper jaw shorter than lower jaw; gape slightly oblique, extending to level of middle of pupil; lips well-developed. Maxillary teeth is a broad band, longitudinally divided by toothless groove, intermaxillary and vomerine teeth form a broad band separated from those of maxillaries and either sides by a concave toothless groove; posteriorly, gradaully tapering and extending as far as back as maxillary teeth; teeth of mandibles separated at symphysis by a groove, and each band likewise divided lengthwise by a groove; the series of teeth in both upper and lower jaws much reduced posteriorly. Tongue well-developed, its tip and sides free. Gill-opening small, crescent in shape, as wide as width of pectoral base. Scales not obvious. Lateral line developed with about 40 pores between gillopening and vent. Dorsal and anal fins well-developed, very long, confluent with small caudal fin. Pectoral small, oval, pointed posteriorly.

Color in formalin dark brown above, paler below; dorsal dark, pectoral and anal pale; posterior parts of dorsal and anal fins, and caudal edge with black.

Based on the specimens sent to the authors, the elvers collected in January and February 1974 in Cagayan Estuary consisted mainly of Anguilla marmorata and A. bicolor pacifica, with occasional occurrence of $A$. japonica. Although accurate species composition 


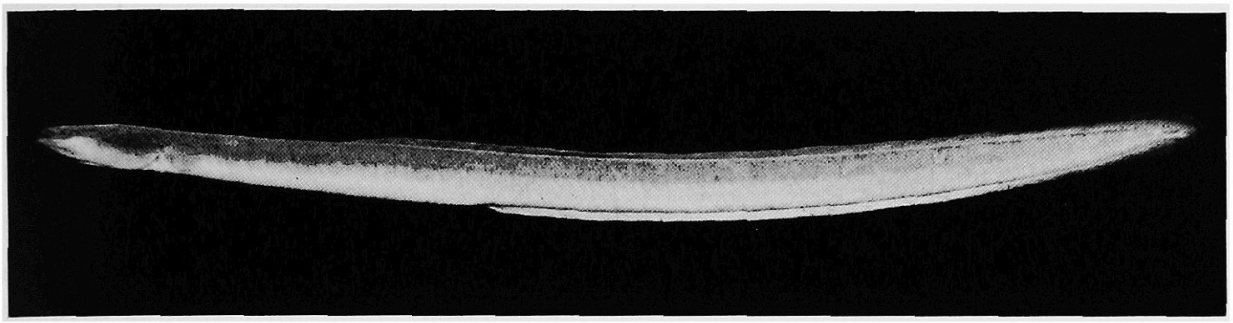

Fig. 1. Anguilla japonica from Luzon Island, the Philippines. Cat, SUF PH-74-1005, $281.0 \mathrm{~mm}$ in total length.

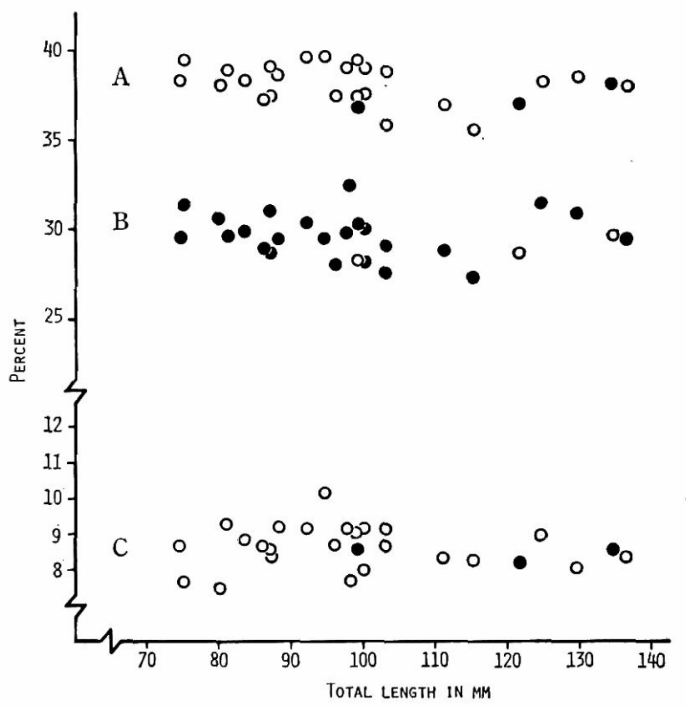

Fig. 2. Change of body proportions during growth in $A$. japonica from the Philippines and Nagata River, Shimonoseki, Japan.

A, preanal length/total length: solid circle, from the Philippines; open circle, from Nagata River.

B, predorsal length/total length: open circle, from the Philippines; solid circle, from Nagata River.

C, ano-dorsal length/total length: solid circle, from the Philippines; open circle, from Nagata River.

of elvers was not studied, Mr. Imamura was of the opinion that the Japanese eel constituted 0-10\%, mostly 1-2\%, of the elvers collected. Some 2000 specimens derived from elvers collected in March-May and August-November 1974 were also sent to the authors, who did not find any Japanese eel in these specimens.

\section{Discussion}

Herre $^{3)}$ recorded four species of eels from the Philippines: A. mauritiana, A. celebesensis, A. australis and A. spengeli. He later revised A. mauritiana and A. australis to 
A. marmorata and A. pacifica, respectively. ${ }^{4)}$ On the other hand, $\mathrm{EGE}^{1)}$ recognized three species and subspecies in the Philippines: A. marmorata, A. celebesensis and A. bicolor pacifica; $A$. spengeli and $A$. pacifica were synonymized with the last subspecies. The present specimens are characterized in having 115 and 116 total vertebrae, 8-10 ano-dorsal vertebrae (ano-dorsal space $8.0-9.1 \%$ of the total length), and no variegated marking. These characters do not correspond with those of the species mentioned above., ${ }^{1,3)}$ The combination of geographical distribution and the sectional counts of vertebrae, arrangement of maxillary, intermaxillary and vomerine teeth, and body color of the specimens fit only $A$. japonica among the known 19 species and subspecies of eels. ${ }^{1,2}$ Consequently, the authors positively identified the specimens as Anguilla japonica. The body proportions the of three smaller specimens correspond well with those of the Japanese eel collected in Nagata River, Shimonoseki, Japan (Fig. 2). As a result of the present study, four species and subspecies of eels can be recognized from the Philippines; a key to the species is given below: $:^{1,2}$

$a_{1}$ Ano-dorsal vertebrae less than 2 (short finned eel) ........ A. bicolor pacifica

$a_{2}$ Ano-dorsal vertebrae more than 7 (long finned eels)

$b_{1}$ Total vertebrae less than 111, variegated markings on the side of body

$c_{1}$ Ano-dorsal vertebrae $13-17$ (mean 15) ............. marmorata

$\mathrm{c}_{3} \quad$ Ano-dorsal vertebrae $8-12$ (mean 10$) \ldots \ldots \ldots \ldots$. celebesensis

$b_{2}$ Total vertebrae more than 112, ano-dorsal vertebrae 7-10 (mean 9), uniform color on the side of body .................. japonica

The elver of the Japanese eel can be distinguished easily from all other elvers of the Philippine eels in lacking the caudal pigment. ${ }^{1,2)}$

\section{Acknowledgement}

The authors wish to express their thanks to Mr. Tomohiro IMAMURA, an expert on eel culture, Quezon City, the Philippines, for help in collecting the samples and information available. Dr. Tetsushi Senta and Mr. Tan Sen Min, Marine Fisheries Research Department, SEAFDEC, Singapore, kindly read and improved the manuscript.

\section{References}

1) V. EGE: Dana-Rep., 16, 1-256 (1939).

2) O. Tabeta, T. Takai, and I. Matsui: Japan. J. Ichthyol., 22 (In press).

3) A. W. Herre: Philippine J. Sci., 23, 123-236 (1923).

4) A. W. Herre: Fish and Wildlife Service, United States Department of the Interior, Research Report 20, 1-977 (1953). 